\title{
Non-invasive Technology Research on Identifying and Locating Short- circuit Fault for Power Supply Network
}

\author{
Xianxu Huo ${ }^{1, *}$, Yongbiao Yang $^{2}$, Jiancheng $\mathrm{Yu}^{1}$, Tianchun $\mathrm{Xiang}^{1}$, Jie Song ${ }^{2}$, Jinming Wang ${ }^{2}$ \\ ${ }^{1}$ State Grid Tianjin Electric Power Company, Tianjin 300010, China \\ ${ }^{2}$ NARI Technology Development Co., Ltd., Nanjing 211106, China
}

\begin{abstract}
Non-invasive fault monitoring and locating system due to the low installation and maintenance cost and non-invasive the use house, has become an important development direction of load short-circuit fault identification and positioning. The paper constructs the overall architecture of non-invasive electricity safety monitoring systems and the test platform of the short circuit-faults, analyse short-circuit current feature, and proposes a non-invasive short-circuit fault identification and location algorithm based on short-circuit mutational current and direct component in the power supply network. This algorithm solves the key technical problems of short-circuit current criterion when breaker operates under the non-invasive fault monitoring architecture, and effectively identifies and locates the rough region of short-circuit fault for the power supply network. If the low voltage feeder circuit smart meter can transmit the fault massage to the main station, the algorithm can locate the fault precisely.
\end{abstract}

\section{Introduction}

Due to the equipment maintenance,the power supply specification configuration and power consumption safety is not in place, power use exist various hidden dangers, prone to electricity fault, one of the most common fault is short circuit. when short-circuit happens, a large currents will flow through the short circuit, to a certain extent it will affect the normal users, meanwhile the short point produces the electric spark or arc and a lot of heat ${ }^{[1-5]}$, even cause equipment damage or fire when it's serious. While present generally algorithm to deal with the short circuit faults is using the high-speed circuit breaker, making the building manager is not clear about the frequency, time and location of the short circuit faults, requiring a lot of human labour to troubleshooting.

Based on non-invasive monitoring load theory ${ }^{[6-7]}$, the paper constructs the overall architecture of non-invasive fault electricity safety monitoring systems and the test platform of the short circuit-faults, analyses the shortcircuit current character, and proposes a non-invasive short circuit fault identification and positioning algorithm based on short-circuit mutational current and direct component in power supply network, making it possible to detect the short-circuit fault and realize the rough location of fault region, if the fault massage can be transmitted to the main station, this algorithm can locate precise positioning of the fault region

\section{Non-invasive electricity safety monitoring systems}

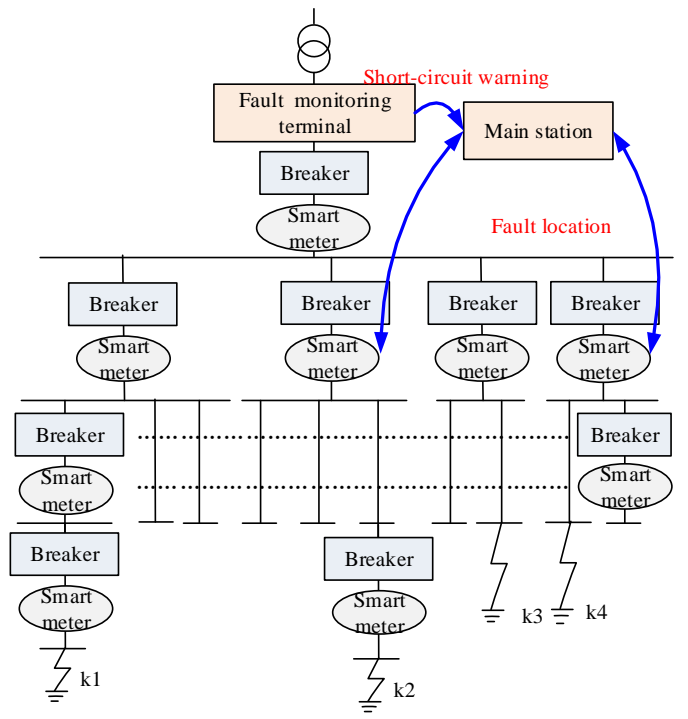

Figure 1. Overall architecture for non-invasive electricity safety monitoring systems

System is mainly composed of main station, fault monitoring terminal, smart meter, communication networks, etc. as explained below:

(1) Main station

The main station mainly realizes the function of analysing the protect-action fault, and gives accident analysis report, including fault types, fault region, cause analysis, etc.

(2) Fault monitoring terminal

Fault monitoring terminal installs at the service entrance of the power supply network, which is the noninvasive important devices for identifying and locating the short-circuit fault. It adopts inbuilt short circuit fault analytic algorithm to analyze three phase current waveform in real time, sending short circuit alarm 
information to the main station. The possible fault location list is generated by the precise location algorithm and communication between main station and smart meter.

(3) Smart meter

Each monitored circuit installs a smart meter, the main station communicate with the smart meter to read loop current condition, if the current turns to zero, shortcircuit protection is probably happened. Besides, smart meter can also be used to monitor the voltage condition of this feeder circuit.

(4) Communication network

Communication network, including RS-485 bus, the Ethernet, wireless communication, etc, is constructed to transmit the data from fault monitoring terminal, smart meters, electric motor and transformer intelligent protection device to the main station

\section{Characteristic analysis of non-invasive short-circuit mutational current}

In order to study the characteristic of the short-circuit mutational current, the paper constructs the test platform shown in figure 2, to prevent the plastic circuit breaker tripping, three layers of circuit breaker have installed in the test circuit, to make sure only the master air switch and end air switch operate, when short circuit happens in the room. Current waveform is directly displayed on the oscilloscope, the waveform can also be collected and stored by data acquisition card.

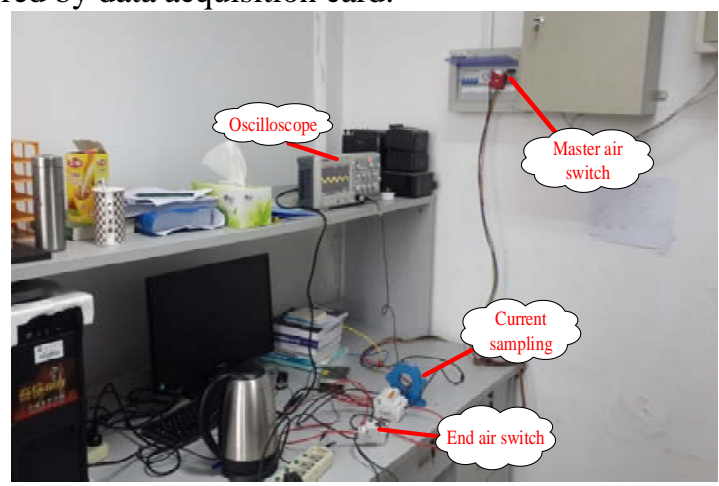

Figure 2. Test platform of current characteristic

The test results are shown in figure 3 and result analysis is as fellow:

(1)As the result of single-phase short circuit shows, there is a high break current, about 500 600A, and obvious direct component less than 10ms, mainly focusing in the 5-10 ms period

(2)As the result of two-phase short circuit shows, short-circuit mutational current can be up to 900A, there is also obviously direct component, mainly focusing in the 5-10 ms period.

(3)As the result of three-phase short circuit shows, the three-phase short circuit current break, up to 500 1200A, there is also obvious direct component, mainly focusing in the 5-10 ms period.

Overall, the single-phase, two-phase and three-phase short-circuit current have obvious direct component, and the short-circuit mutational current is huge, can be reach
$500 \mathrm{~A}$, the time of the short-circuit fault mainly focus during $5 \mathrm{~ms}$ and 10ms.Therefore, the paper proposes a short-circuit fault location criterion based on short-circuit mutational current and direct component.

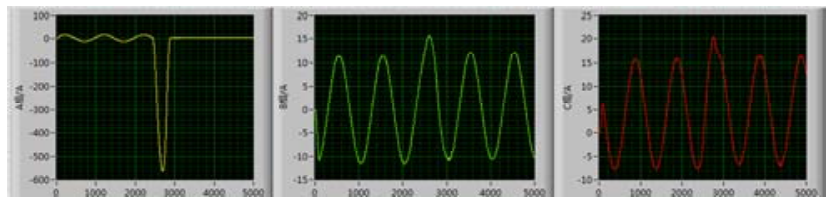

(a) Current waveform of single-phase short circuit

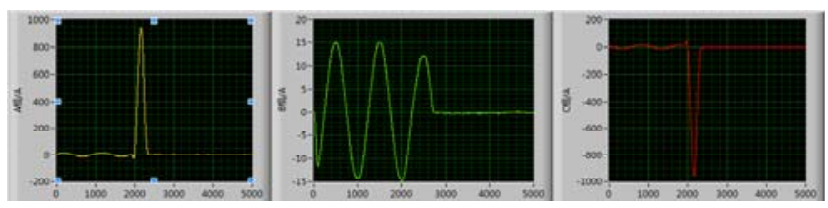

(b) Current waveform of two-phase short circuit

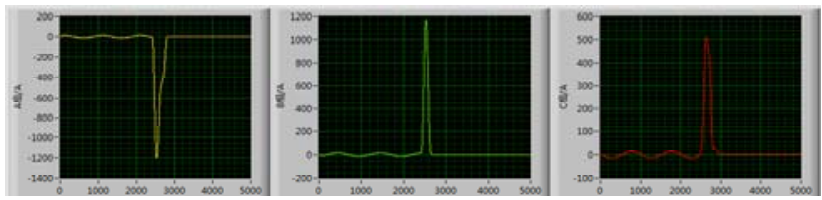

(c) Current waveform of three-phase short circuit

Figure 3. Current waveform of short circuit

\section{Non-invasive Short-circuit fault criterion}

The paper proposes non-invasive short-circuit fault criterion for power supply network based on short circuit mutational current and direct component, as below in figure 4.

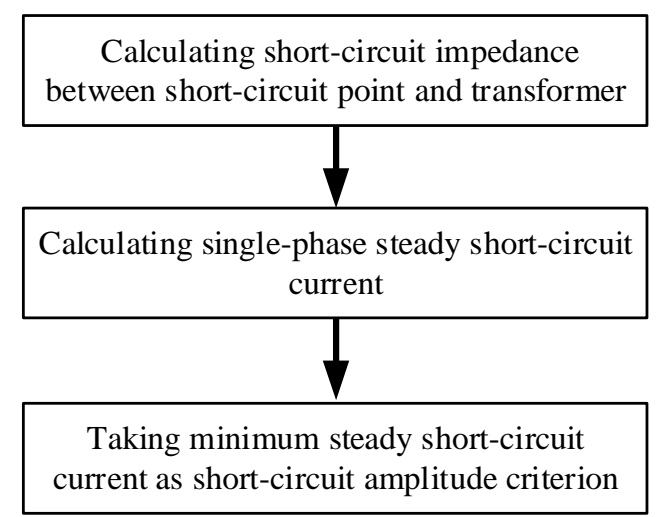

Figure 4. Short-current fault criterion

Step 1, Calculating short-circuit impedance between short-circuit point and transformer in the power supply network.

Step 2, Calculating steady short-circuit current of all possible short-circuit point, and then taking minimum steady short-circuit current as short-circuit amplitude criterion $P_{\mathrm{M}}$.

If the mutational current amplitude is greater than amplitude criterion, short circuit happens. Meanwhile, the mutational current direct component is taken as an auxiliary criterion that if it is greater than $0.25 P_{\mathrm{M}}$, short circuit happens surely. 


\subsection{Example analysis}

The Distribution system of dormitory for a bus station is taken as an example to illustrate the setting process of short-circuit current criterion. The circuit of distribution system is shown in figure 5 .

The common single-phase short circuit is taken as an example to calculate steady short-circuit current. To simplify the calculation, the loo of the bus, smart meter and low-voltage switch are ignored. Assuming that the superior power system is infinite power system, and the primary voltage of transformer equivalent to the secondary side is $230 \mathrm{~V}$. WPn is the loop mark of distribution cabinet, $\mathrm{k} 1 \sim \mathrm{k} 4$ is selected as the typical short-circuit point.

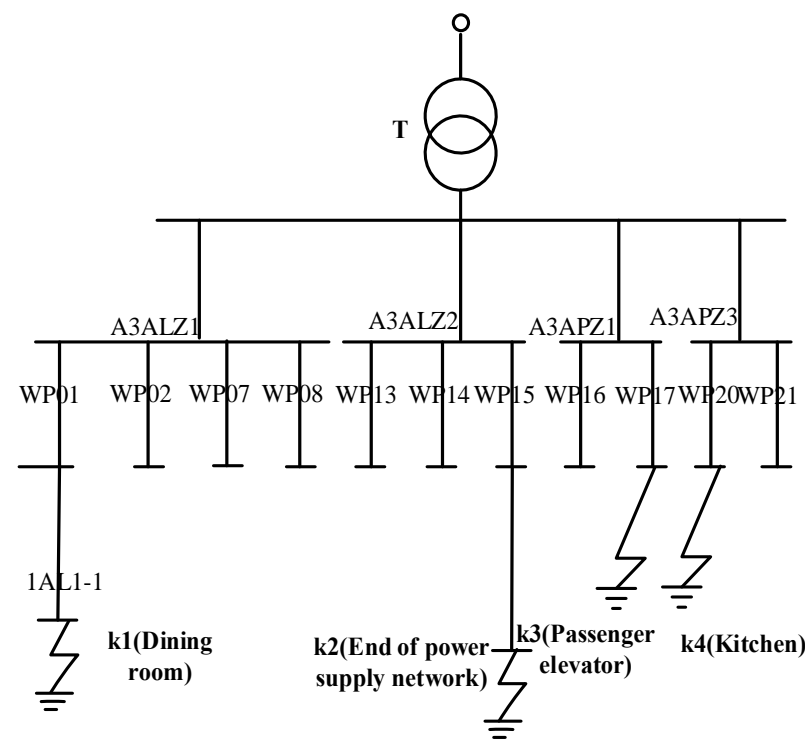

Figure 5 distribution system of dormitory for bus station

In order to analyze the short-circuit current in the ratio of total current, the algorithm of load equivalent impedance is adopted to calculate load current. the calculation formulas for the load impedance $Z_{L n}$ of the line:

$$
\begin{gathered}
Z_{\mathrm{Bn}}=\frac{U_{\mathrm{N}}^{2}}{P_{\mathrm{n}} / \cos \varphi} \\
Z_{\mathrm{Ln}}=\frac{U_{\mathrm{N}}^{2}}{\kappa_{\mathrm{L}} S}=\frac{Z^{*} \cdot Z_{\mathrm{Bn}}}{\kappa_{\mathrm{L}}}
\end{gathered}
$$

Where:

$U_{\mathrm{N}^{-} \text {-voltage rating }}(230 \mathrm{~V})$;

$P_{\mathrm{n}}$--single-phase capacity $(\mathrm{kW})$;

\begin{tabular}{|c|c|c|c|}
\hline Table & Per-unit & load & impedance \\
\hline \multicolumn{2}{|r|}{ load } & \multirow[b]{2}{*}{$\cos \varphi$} & \multirow{2}{*}{$\begin{array}{c}\text { per-unit } \\
\text { impedance }\end{array}$} \\
\hline type & name & & \\
\hline rotary load & asynchronous motor & 0.8 & $0.09+\mathrm{j} 0.154$ \\
\hline \multirow{4}{*}{ static load } & incandescent & 1 & 1 \\
\hline & gas discharge lamp & 0.85 & $0.85+\mathrm{j} 0.53$ \\
\hline & rectifier device & 0.9 & $0.9+\mathrm{j} 0.44$ \\
\hline & heater & 0.9 & $1+\mathrm{j} 0.49$ \\
\hline
\end{tabular}

$\mathrm{Z}^{*}$--per-unit load impedance, as shown in table 1 ;

According to the formula (1), (2) and per-unit load impedance of table 1 , the load equivalent impedance and line impedance can be calculated in table 2 :

Table 2. Load equivalent impedance and line impedance

\begin{tabular}{|c|c|c|c|}
\hline mark & $\begin{array}{c}\text { computing } \\
\text { load kW }\end{array}$ & $\begin{array}{c}\text { load equivalent } \\
\text { impedance } \boldsymbol{\Omega}\end{array}$ & $\begin{array}{c}\text { line impedance } \\
\mathbf{~} \boldsymbol{\Omega}\end{array}$ \\
\hline WP01 & 15 & $2.469+\mathrm{j} 1.398$ & $2.775+\mathrm{j} 0.79$ \\
\hline 1AL1-1 & 9 & $4.113+\mathrm{j} 2.331$ & $21.06+\mathrm{j} 1.64$ \\
\hline WP02 & 21.3 & $1.641+\mathrm{j} 1.023$ & $2.775+\mathrm{j} 0.79$ \\
\hline WP07 & 9.5 & $4.125+\mathrm{j} 2.016$ & $144.612+\mathrm{j} 4.888$ \\
\hline WP08 & 12.7 & $3.093+\mathrm{j} 1.512$ & $111.894+\mathrm{j} 5.916$ \\
\hline WP13 & 49.3 & $0.75+\mathrm{j} 0.426$ & $2.565+\mathrm{j} 1.368$ \\
\hline WP14 & 49.3 & $0.75+\mathrm{j} 0.426$ & $3.42+\mathrm{j} 1.824$ \\
\hline WP15 & 49.3 & $0.75+\mathrm{j} 0.426$ & $4.56+\mathrm{j} 2.432$ \\
\hline WP16 & 3.7 & $1.113+\mathrm{j} 1.626$ & $89.454+\mathrm{j} 3.196$ \\
\hline WP17 & 15 & $0.232+\mathrm{j} 0.399$ & $66.36+\mathrm{j} 6.636$ \\
\hline WP20 & 13.3 & $3.267+\mathrm{j} 1.602$ & $34.76+\mathrm{j} 3.476$ \\
\hline WP21 & 13.3 & $3.267+\mathrm{j} 1.602$ & $34.76+\mathrm{j} 3.476$ \\
\hline
\end{tabular}

According to the load equivalent impedance and line impedance calculated above, and the formulas $I_{\mathrm{T}}=\frac{U_{\mathrm{N}}}{\left|Z_{\mathrm{R}}\right|}$, $U=I_{\mathrm{T}} \cdot\left(Z_{\mathrm{R}}-Z_{\mathrm{T}}\right),\left(Z_{\mathrm{R}}\right.$ is defined as short-circuit impedance, transformer impendence $Z_{T}=1.875+j 9 m \Omega$ ), the steady short-circuit current and voltage of transformer at typical short-circuit point are calculated in table 3 .

Table 3. Current and voltage of transformer at typical shortcircuit point

\begin{tabular}{|c|c|c|}
\hline $\begin{array}{c}\text { typical short-circuit } \\
\text { point }\end{array}$ & $\begin{array}{c}\text { current of } \\
\text { transformer A }\end{array}$ & $\begin{array}{c}\text { voltage of } \\
\text { transformer V }\end{array}$ \\
\hline no short circuit & 995 & 223 \\
\hline k1: dining room & 8625 & 190 \\
\hline $\begin{array}{c}\text { k2: end of power } \\
\text { supply network }\end{array}$ & 1179 & 222 \\
\hline k3: passenger elevator & 3192 & 217 \\
\hline k4: kitchen & 6505 & 201 \\
\hline
\end{tabular}

The following conclusions can be drawn from table 4:

1) The load current is about $1000 \mathrm{~A}$, and secondary side voltage is $223 \mathrm{~V}$ without a short circuit.

2) To simplify the analysis, Assuming that the total load current is constant (995A) when short-circuit occurs.

When short circuit occurs at end of power supply network k2, the steady short-circuit mutational current is only about 200A; While it occurs at the shortest point k1, the steady short-circuit mutational current is about 7500A, which is 40 times of k2. The secondary side voltage of transformer ranges from 190A to 220A.

The minimum short-circuit current is 0.2 times of normal load current ratio, accompanying with $40 \mathrm{~kW}$ jump, generally there won't be so big a load jump.

Non-invasive short-circuit fault criterion of this example, based on short-circuit mutational current and direct component, is set as fellow:

(1) Short-circuit current amplitude ranges from 200A to $7500 \mathrm{~A}$, so minimum steady short-circuit current $200 \mathrm{~A}$ is selected as short-circuit amplitude criterion $P_{\mathrm{M}}$.

(2)The period of short-circuit current is about 5ms$10 \mathrm{~ms}$, and the direct component of the mutational current is huge, so $0.25 P_{\mathrm{M}}(50 \mathrm{~A})$ is set as the direct component criterion. 


\section{Non-invasive location algorithm}

short-circuit

The single-phase short-circuit fault of power supply network is taken as an example to describe the algorithm on identifying and locating the fault. The short-circuit fault location algorithm is shown in the figure 5 .

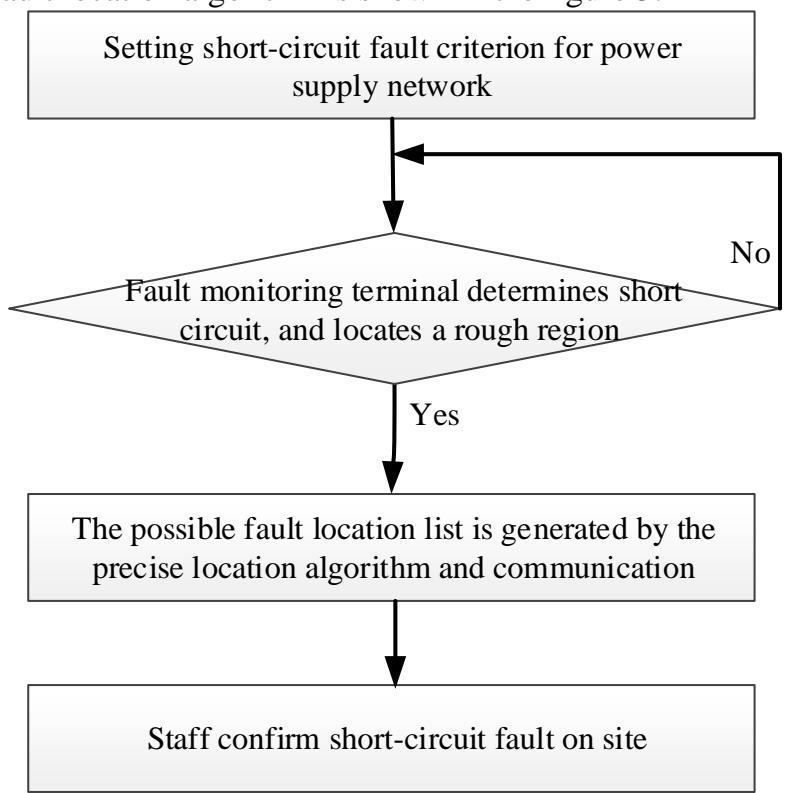

Figure 5. Overall process for short-circuit fault location

(1) Step 1, setting criterion

Setting short-circuit fault criterion for power supply network based on short-circuit mutational current and direct component.

(2) Step 2, monitoring short-circuit fault in real time, and locating a rough region

Fault monitoring terminal analyses current waveform in real time by the inbuilt wavelet analysis and shortcircuit fault analysis algorithm, and then determines if short circuit occurs. If short circuit occurs, the terminal will display the massage of short-circuit fault on the human-computer interface, and send the message to the main station.

(3) Step 3, locating precisely

After receiving the alarm message of short-circuit fault, the main station will start precise location algorithm, and communicate with smart meter installed on the distribution line (read firstly the massage from smart meters specified by the step 2). If there is no communication network between the main station and smart meters, the main station will generate the possible fault location list.

(4) Step 4, confirming short-circuit fault on site

The staff confirm short-circuit fault on site by the possible fault location list.

Once the situation of artificial outage is eliminated, it shows that short-circuit fault locates on the line without the smart meter. After confirming the short-circuit fault location, Staff collects the fault location information.

\section{Conclusion}

The paper proposes a new non-invasive electricity safety monitoring system, composed of main station, fault monitoring terminal, smart meters, communication networks, etc. Algorithm on identifying and locating short-circuit fault for power supply network is researched and developed. Besides, the distribution system of dormitory is taken as an example to set the process of short-circuit fault criterion in detail to provide the threshold criterion of short-circuit current.

The identification and location algorithm of shortcircuit fault for non-invasive electricity safety monitoring system solves the key technical problems of short-circuit current criterion when breaker operates under the noninvasive fault monitoring architecture, and effectively identifies and locates the rough region of short-circuit fault for the power supply network. If the low voltage feeder circuit smart meter can transmit the fault massage to the main station, the algorithm can locate the fault precisely. Based on non-invasive monitoring load theory, the non-invasive electricity safety monitoring device has extensive application value to identify and locate shortcircuit fault.

\section{Acknowledgements}

This work was supported by the Science and Technology Foundation of State Grid Corporation (SGTJDK00DWJS1500097).

\section{References}

[1] H. Fan, J. Ren, W. Cao. The Non Intrusive Fault Localization and Identification Algorithm for Low Voltage Distribution Network. Electrical Engineering, 11, 66-69 (2014)

[2] J. Wang, X. Miao. Modeling and Simulation of Single-phase Short Circuit Fault in Low Voltage Distribution System. Low Voltage Apparatus, 22, 1517 (2012)

[3] J. Yong, X. Gui, L. Niu, L. Zeng. Series Arc Fault Identification in Low Voltage System Based on Autoregressive Parameter Model. Transactions of China Electrotechnical Society, 26, 213-214 (2011)

[4] X. Peng, G. Qian, X. Li. Intelligent Trip-out Fault Diagnosis of Overhead Transmission Line. High Voltage Engineering, 38, 1965-1971 (2012)

[5] J. Tang, X. Yin, Z. Zhang, C. Yang. Survey of fault location technology for distribution networks. Electric Power Automation Equipment, 33, 7-11 (2013)

[6] P. Li, Y. Yu. Nonintrusive Algorithm for On-Line Power Load Decomposition. Journal of Tianjin in University, 42, 303 (2009)

[7] Y. Yu, B. Liu, W Luan. Nonintrusive Residential Load Monitoring and Decomposition Technology. Southern Power System Technology, 7, 1-4 (2013) 